Research Article

\title{
Numerical Simulation and Optimization of Wind Effects of Porous Parapets on Low-Rise Buildings with Flat Roofs
}

\author{
Ye Qiu (iD, Bingbing San $(\mathbb{D}$, and Youyi Zhao $\mathbb{D}$ \\ College of Civil and Transportation Engineering, Hohai University, Nanjing 210098, China \\ Correspondence should be addressed to Bingbing San; sanbingbing@163.com
}

Received 8 January 2019; Accepted 28 March 2019; Published 14 April 2019

Academic Editor: Ignacio Paya-Zaforteza

Copyright (C) 2019 Ye Qiu et al. This is an open access article distributed under the Creative Commons Attribution License, which permits unrestricted use, distribution, and reproduction in any medium, provided the original work is properly cited.

\begin{abstract}
This paper presents a procedure to optimize the porosity of parapets to improve the aerodynamic behavior of low-rise buildings with flat roofs, by coupling an optimization algorithm and computational fluid dynamics (CFD) simulations. The performance of solid parapets to decrease the wind suctions on flat roofs induced by conical vortices was firstly studied, based on four turbulence closure models (standard $k-\varepsilon$, RNG $k-\varepsilon$, SST $k-\omega$, and RSM). The simulation results were validated by comparing with the wind tunnel data. Additionally, the porous parapet was treated as a momentum sink in the governing momentum equation, and the RSM turbulence model was employed. As a result, six optimization studies focusing on the highest mean suction minimization that consider parapet height were presented. The aim of this paper is to search for the best performing porosity through an automatic CFD-based optimization methodology. At low relative heights $\left(h_{\mathrm{p}} / H=0.01 \sim 0.05, h_{\mathrm{p}}\right.$ is the parapet height, and $H$ is the roof height), the porous parapet with optimal porosity in between $38.2 \%$ and $52.3 \%$ seems to be more effective than solid parapets in attenuating high corner suctions generated by conical vortices; however, the solid parapet gives the best performance in the reduction of wind suctions when $h_{\mathrm{p}} / H \geq 0.07$.
\end{abstract}

\section{Introduction}

Wind loads on flat or low-sloped roofs of low-rise buildings have been evaluated in many wind tunnel investigations. Of particular concern are the worst mean and peak suctions observed on roof corners near the edge for oblique wind directions, where the existence of conical or delta wing vortices is well established at both model scale and full-scale [1]. This phenomenon becomes increasingly important for the design of low industrial buildings, because of their relatively light dead load and flexibility that making them susceptible to wind loads. Various types of parapets, such as solid parapets, partial or porous parapets, and rooftop spoilers, were widely used in the past to reduce high corner suctions caused by the conical vortices [2-6].

A number of porous parapet configurations have been investigated in wind tunnel and full-scale experiments by previous researches. Surry and Lin [7] found that porous parapets are the most effective parapet configuration, leading to a reduction of the corner suctions of up to about
$70 \%$. The porous parapets are expected to (a) disrupt the formation of the corner vortices, (b) absorb some of the flow energy over the roof edges, and (c) generate weakened vortices that formed over the top edge of the parapet by displacing them away from the roof. Banks [8] examined three porous parapet configurations: a mesh of $50 \%$ porosity, a porous parapet with circular holes having $50 \%$ porosity, and a slatted fence. They suggested that the effectiveness of the three parapet types is similar, with circular holed parapet providing marginally better results. Pindado and Meseguer [9] conducted tests with six porous parapet types and found that low relative height parapets $\left(h_{\mathrm{p}} / H<0.05\right)$ with a medium porosity are more effective than solid parapets to reduce the corner suctions. Kopp et al. [10] also tested a porous perimetric parapet with $50 \%$ porosity, which can efficiently mitigate roof suctions in the corner, edge, and interior zones as defined by ASCE 7-16 [11]. Lin et al. [12] and Blessing et al. [13] carried out full-scale measurements, utilizing a 6-fan Wall of Wind (WoW) testing apparatus, to investigate the effect of modified roof edge shapes in 
reducing the peak suctions for the wind direction of $45^{\circ}$. They found the cantilever AeroEdge ${ }^{\mathrm{TM}}$ screen with about $50 \%$ porosity reduced the peak suction up to $75 \%$ in the roof corner compared to the conventional edge shape (i.e., vertical solid parapet).

More recently, several studies by means of computational fluid dynamics (CFD) simulations were carried out to investigate the performance of solid parapets in reducing the roof suctions of low-rise buildings. Poitevin et al. [14] numerically studied surface pressures on open canopy structures with solid parapets. They found that CFD simulations, by using Reynolds-averaged Navier-Stokes (RANS) equations with proper turbulence models, are in good agreement with the wind tunnel results. Liu et al. [15] applied standard $k-\varepsilon$ turbulence model to the wind field of flat roof with solid parapets, and the effect of wind direction was analyzed in detail, incorporated with wind tunnel testing. Li and Liu [16] investigated the unsteady features of conical vortices on a flat roof on the basis of large eddy simulation (LES). The study shows that the addition of solid parapet can mitigate the peak corner suctions, and the dimension of the conical vortices becomes larger with increasing parapet height. Aly and Bresowar [17] carried out an aerodynamic mitigation study of wind-induced lift forces on low-rise buildings using the $k-\varepsilon$ and RSM turbulence models, and the mitigation features includes solid parapets (barriers), circular edges, inclined edges, and airfoil edges. The numerical results revealed that solid parapets can bring a significant reduction in the lift force of about $20 \%$ but increase the drag force on the whole structure (building and parapet) by $32.8 \%$. It is noted that none or little attention has been paid on the CFD simulations of wind effects of porous parapets on low-rise buildings. Despite that, porous fences have been widely used for wind protection in many technical applications, ranging from dust erosion control to pedestrian comfort [9].

To the authors' knowledge, experimental methods using wind tunnel testing or CFD techniques provide the basis of traditional "cut and try" approach for the design of parapets located at roof edges. In this approach, several parapets with different porosities or heights are investigated, and the one that yields the best performance in reducing high suctions is identified. With the rapid development of computer hardware performance and CFD techniques in recent years, a number of optimization algorithms have been proposed in the literatures for a variety of applications including CFDbased aerodynamic shape or porosity optimization [18-20]. One relevant study by San et al. [20] conducted the aerodynamic porosity optimization of wind fences for the shelter effect using the gradient algorithm, and the optimal fence porosities of $10.2 \%$ and $22.1 \%$ were determined, which provide the best shelter effect in the near and far wake regions, respectively. However, none or little effort has been dedicated to the optimization study of roof-edge parapets, which can help search for an optimal porosity or configuration of parapets for mitigating high corner suctions on building roofs more efficiently.

The main objective of the current paper is to propose a CFD-based optimization methodology to optimize the parapet porosity, for improving the aerodynamic behavior of low-rise buildings with flat roofs. In the first part of this paper, different turbulence closure models (standard $k-\varepsilon$, RNG $k-\varepsilon$, SST $k$ - $\omega$, and RSM) were employed to simulate the effects of solid parapets on the wind pressure distributions on a flat roof and were evaluated using the wind tunnel data of Stathopoulos et al. [5]. Additionally, the porous parapet was treated as a momentum sink in the governing momentum equation. Analogical CFD simulation analysis of surface pressures on the ground and a triangular prism behind a porous fence was conducted and compared with the experimental results [21], in order to validate the numerical method used in this study. In the second part, the influence of the height of solid parapets on roof surface pressures has been analyzed numerically, and six parapets with relative heights $h_{\mathrm{p}} / H$ from 0.01 to 0.13 were selected for the aerodynamic optimization analysis. The implementation of the optimization procedures using gradient algorithm was then carried out to find the optimal porosity, which aims at improving the corner suction mitigation performance of parapets early in the design.

\section{Numerical Methods}

2.1. Governing Equations. Numerical simulations were carried out in this study through the commercial CFD software, ANSYS Fluent 15.0. Airflow is assumed to be steady, incompressible, viscous, and isothermal. The continuity equation and Reynolds-averaged Navier-Stokes (RANS) momentum equation presented in equations (1) and (2), respectively, were solved in each of the simulation cases.

$$
\begin{aligned}
\frac{\partial u_{i}}{\partial x_{i}} & =0, \\
u_{j} \frac{\partial u_{i}}{\partial x_{j}} & =-\frac{1}{\rho} \frac{\partial p}{\partial x_{i}}+\frac{\partial}{\partial x_{j}}\left(\frac{\mu}{\rho} \frac{\partial u_{i}}{\partial x_{j}}-\overline{u_{i}^{\prime} u_{j}^{\prime}}\right)+S_{i},
\end{aligned}
$$

where $x_{i}$ is the Cartesian coordinate and $u_{i}$ is the mean velocity component in the $i$ th direction, $p$ denotes the deviation of pressure from its reference value, and $\rho$ and $\mu$ are the density and dynamic viscosity of the air, respectively. $S_{i}$ is a source term and assumed to be zero everywhere except inside the porous media [22-24], which is treated as a momentum sink as discussed in Section 2.3. $-\overline{u_{i}^{\prime} u_{j}^{\prime}}$ is the Reynolds stress caused by turbulence [23].

Four turbulence closure models were tested to predict the wind effects of parapets on low-rise buildings: standard $k-\varepsilon$ model, Re-Normalization Group (RNG) $k-\varepsilon$ model, Shear Stress Transport (SST) $k-\omega$ model, and ReynoldsStress model (RSM). Details of these turbulence models are given in the ANSYS Fluent 15.0 User's Guide.

2.2. Numerical Validation by Stathopoulos's Experiment. Stathopoulos et al. [5], denoted STA hereafter, has experimentally measured the surface pressure coefficients on flat roofs with solid parapets for the wind direction of $45^{\circ}$. Thus, in order to validate the possible applicability of the turbulence closure models used later (standard $k-\varepsilon$, RNG $k-\varepsilon$, SST $k-\omega$, and RSM) for solving these cases, the mean pressure 
study results from STA's experiments are compared. Dimensions of the building model are length $(L) \times$ width $(W) \times$ height $(H)=150 \mathrm{~mm} \times 150 \mathrm{~mm} \times 75 \mathrm{~mm}$. Perimetric parapets with height $h_{\mathrm{p}}=5 \mathrm{~mm}$ are continuous around all four walls of the building, which corresponds to $1 \mathrm{~m}$ in full-scale (using a model scale of $1: 200$ ). STA's experiments were performed in an open country boundary layer $(z<50 \mathrm{~m})$ of that wind tunnel, which has a roughness length, $z_{0}$, of approximately $2 \mathrm{~cm}$ at a scale of $1: 200$. The mean velocity profile has a power law exponent $\alpha=0.15$ and is given by

$$
\frac{u(z)}{u_{\text {ref }}}=\left(\frac{z}{z_{\text {ref }}}\right)^{\alpha}
$$

where $u_{\mathrm{ref}}=13 \mathrm{~m} / \mathrm{s}$ is the wind speed at the reference height $\left(z_{\text {ref }}=600 \mathrm{~mm}\right)$. Figure 1 shows the inlet velocity profile normalized with $u_{\text {ref. }}$. Note that we do not have the experimental data about inlet profiles of turbulence kinetic energy $\left(k_{\mathrm{in}}\right)$ and its dissipation rate $\left(\varepsilon_{\mathrm{in}}\right)$ and specific dissipation rate $\left(\omega_{\text {in }}\right)$. Thus, the inlet boundary conditions for $k_{\text {in }}, \varepsilon_{\text {in }}$, and $\omega_{\text {in }}$ have been obtained from the assumption of equilibrium boundary layer:

$$
\begin{aligned}
& k_{\mathrm{in}}=\frac{3}{2}\left(I_{\mathrm{u}} u\right)^{2}, \\
& \varepsilon_{\mathrm{in}}=\frac{\left(C_{\mu}^{3 / 4} k_{\mathrm{in}}^{3 / 2}\right)}{\kappa z}, \\
& \omega_{\mathrm{in}}=\frac{k_{\mathrm{in}}^{1 / 2}}{\left(C_{\mu}^{1 / 4} \kappa z\right)},
\end{aligned}
$$

where $\kappa$ is the von Karman constant with the value of 0.4 $[25,26] ; I_{\mathrm{u}}$ is the free-stream turbulence intensity and is about $2.5 \%$ at the building height $(H=75 \mathrm{~mm})$ in the simulated boundary layer. No slip condition and standard wall functions have been considered for the ground, building surfaces, and solid parapets. Free slip conditions were assumed for the top and side boundaries. Outlet conditions in terms of zero normal gradients for all variables were adopted, and the outlet flow has been considered fully developed (outflow).

Figure 2 presents the schematic illustration of the computational domain, and a multiblock structured grid system (hexahedral grids) has been used for the space discretization. Dimensions of the domain are $42 \mathrm{H}$ (length) $\times$ $26 H$ (width) $\times 8 H$ (height), which leads to a blockage ratio around $1.5 \%$. The building was located at $1 / 4$ of the domain length from the inlet boundary. Also, simulations with a domain height of $16 \mathrm{H}$ have been conducted and negligible changes in the results $(<1 \%$ in the maximum of mean pressures on the flat roof) have been found, which reveals that $8 H$ was considered high enough without being affected by the boundary conditions imposed at $z=8 \mathrm{H}$. The domain was split into two subdomains (inner cylindrical region and outer region) as it is shown in the insets in Figure 2. The two subdomains were connected via a nonconformal interface with tetrahedral grids to improve the quality of the mesh in a fully resolved boundary region [27]. Nonuniform spacing grid arrangement was employed for the building model, which has $72 \times 72$ grid points on the roof surface and 48 grid

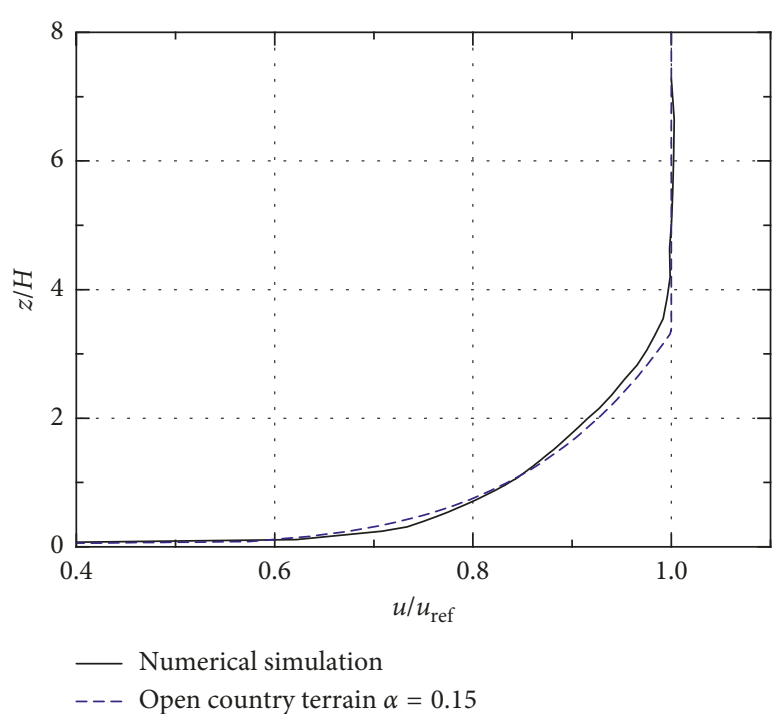

FIgURE 1: Vertical profile of the mean velocity at the inlet boundary.

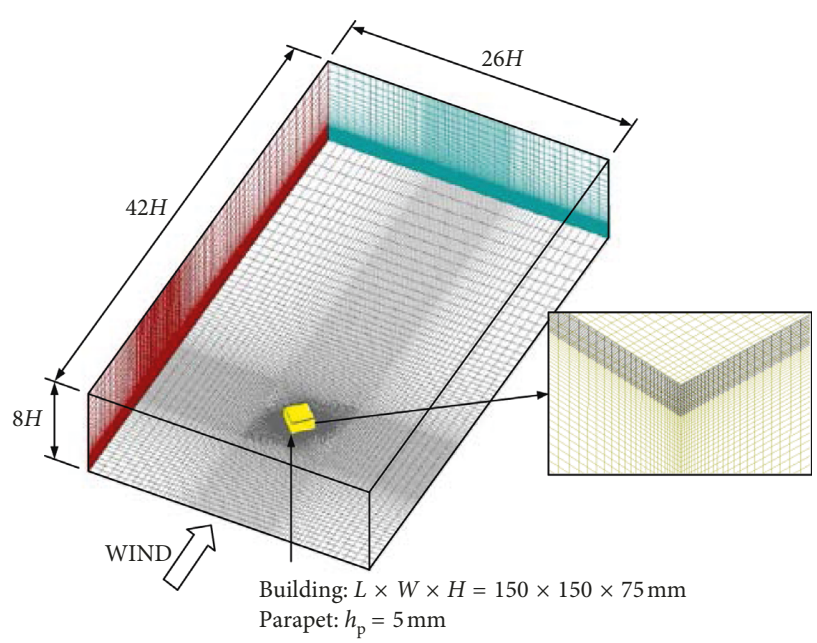

FIgURE 2: Computational domain and structural grid system used in this study.

points along the building height. Note that, more dense grid is required near the roof corner to take account of the steep change of turbulent properties due to the existence of parapet. Therefore, a finer grid with $\Delta x / h_{\mathrm{p}}=0.0625$, $\Delta y / h_{\mathrm{p}}=0.0625$, and $\Delta z / h_{\mathrm{p}}=0.0625$ at the roof corner was adopted, and the expansion ratio in the nonuniform grid system along the building and parapet edges did not exceed 1.3. This resolution grid was found to be enough to obtain correct grid-independent results and was also used for fence flow simulations by Santiago et al. [28]. The entire computational grids keep the maximum expansion ratio of the grids less than 5 , and the estimated values of $y^{+}$on the roof and parapet are between 30 and 60 . The grid comprised totally about two million individual cells after a few grid independency tests.

The governing equations coupled with the boundary conditions have been solved by using a collocated grid 
system based on the finite volume method (FVM). Discretized equations are solved by the segregated solution algorithm. The SIMPLEST algorithm has been employed for the pressure-velocity coupling, which is a modification of the SIMPLE (semi-implicit method for pressure-linked equations) algorithm based on the linkage between pressure and velocity [29]. The SIMPLEST method has been widely used for simulating wind pressure fields, for example, in applications for irregular-plan shape buildings [30] or singlesided ventilated buildings [31]. The solutions were considered converged when the normalized residuals were below $1 \times 10^{-5}$.

Figure 3 compares the mean pressure distributions along the central line of the flat roof obtained from SAT's experiments and present computation results. The data were derived from wind direction of $45^{\circ}$. Surface pressures have been normalized by the mean dynamic pressure $\left(0.5 \rho u_{H}^{2}\right)$ at the building height and are given by $C_{\mathrm{p}}=\Delta p /\left(0.5 \rho u_{H}^{2}\right)$, where $\Delta p$ is the mean pressure difference between the surface pressure and a reference pressure. Figure 3 suggests that the performance of any of the four turbulence models against the wind tunnel data is not particularly good. However, the agreement of RSM turbulence model with experimental measurements is acceptable, although $C_{\mathrm{p}}$ values in the case of parapet height $h_{\mathrm{p}} / H=1 / 15$ are slightly overestimated at $x / L>0.8$. Standard $k-\varepsilon$ model provides, in general, the highest suction at the windward edge and poor performance of the attached flow simulation in the leeward region. This turbulence model is generally inaccurate for flows with adverse pressure gradient and underpredicts the size of recirculating zones in some cases [32]. RNG $k-\varepsilon$ model presents an overprediction of wind suctions in the leeward region for the no parapet case (Figure 3(a)) and near the windward edge for the solid parapet case (Figure 3(b)). Numerical results of SST $k$ - $\omega$ model are worse than those of other turbulence models, which underestimates the absolute values of the mean pressure coefficients. As a result, the RSM model was employed to model surface pressure features in the later simulation procedure. Furthermore, it is noted that there are not detailed test measurements close to the windward corner of the roof. Thus, the turbulence models cannot be verified near the windward corner, and the numerical results obtained there should be observed carefully.

\subsection{Modelling of Interaction of Wind with a Porous Media.} Most previous computational studies modelled wind fences as a porous jump region (assuming a thin fence), e.g., Guo and Maghirang [22], Song et al. [24], Santiago et al. [28], and Lee and Lim [33]. In the present study, porous parapets are also aerodynamically represented in the CFD analyses as porous media. It is assumed that the porous domain of the parapet is homogeneous and isotropic and is treated as a pressure discontinuity surface by using a porous jump model. Thus, a momentum sink (i.e., pressure loss) is added to the momentum equation (2) to model the resistance to the flow following the works of Wilson [34]. For steady-state, incompressible flow through a porous media, the pressure loss can be calculated from the relation $\Delta p=1 / 2 k_{\mathrm{r}} \rho v^{2}$, where $v$ is the normal velocity component and $k_{\mathrm{r}}$ is the pressure loss coefficient, and an empirical formula $k_{\mathrm{r}}=1.04\left(1-\phi^{2}\right) / \phi^{2}$ provided by Reynolds [35] was employed. Here, $\phi$ is the porosity defined as the ratio of the open area to the total area of the porous parapet. Note that $k_{\mathrm{r}}$ tends to be infinite in the case of solid parapet $(\phi=0)$, and as a result, the solid parapet in the simulations was treated as the wall boundary condition.

As far as we are aware, most previous studies focused on the wind effects of solid parapets on roof corners, however, sufficient experimental data are not available for porous ones. It may be the first study to simulate the surface pressures on a flat roof with porous parapets embedded in an atmospheric boundary layer. In order to verify the numerical method used in this study to simulate the porous media flow, the experimental results of Park and Lee [21] were chosen as a benchmark. They carried out the point pressure measurements on the triangular prism model and ground surface along the midspan of the porous fence in an atmospheric boundary layer (power law exponent, $\alpha=0.14$ ).

Figure 4 presents the computational domain and coordinate system for the porous fence and triangular prism model used in the simulations. The height $\left(h_{\mathrm{f}}\right)$ and length of the numerical fence, were the same as the prism crest height ( $h=40 \mathrm{~mm}$ ) and length (18h), respectively. The prism model, with a span of $95 \mathrm{~mm}$, was fixed at a distance of $60 \mathrm{~mm}$ from the fence. Computational domain ranges from $x / h=-15$ to 45 in the streamwise direction and from $z / h=0$ to 15 in the vertical direction with fence located at $x / h=0$. The resolution grid $\left(\Delta x / h_{\mathrm{f}}=0.0625\right.$ and $\left.\Delta z / h_{\mathrm{f}}=0.0625\right)$ close to the fence, and the types of boundary condition (standard wall functions at ground and prism, outflow at outlet boundary, and free slip conditions at the top and side), are the same used in the parapet cases (see Section 2.2). The porous fence is represented as a momentum sink. The structural grid of 22438 cells was used in the domain discretization. This configuration has been simulated by using the RSM turbulence model mentioned above, with the same simulation set up representing STA's experiment. Inlet profiles of the mean velocity and turbulence intensity were obtained from the experimental data and computed in the same way that for parapet cases.

Figure 5 shows the mean pressure distributions around the fence and prism model obtained from the simulation and wind tunnel experiment. It can be seen that fence porosity has a significant influence on the mean pressure distributions on the ground and prism surface. For porous fences of $\phi=20 \%$ and $65 \%$, the present simulation results are in general in a good agreement with the experimental data. This indicated that the porous jump model and turbulence closure model could better predict the surface pressure and flow field around the porous media. Thus, the verified numerical method (porous jump model, turbulence model, boundary conditions, etc.) was applied to predict the wind effects of solid and porous parapets on a flat roof.

\section{Optimization Methods}

3.1. Optimization Model. The essential components of an aerodynamic porosity optimization problem are design 


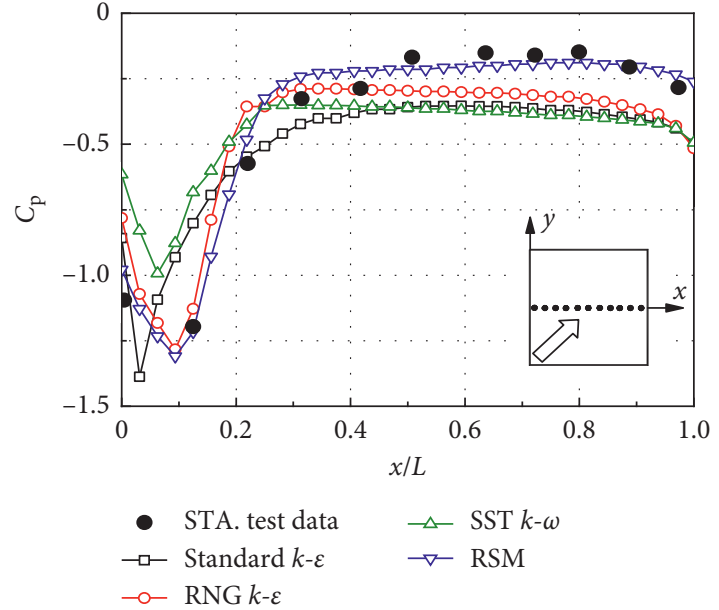

(a)

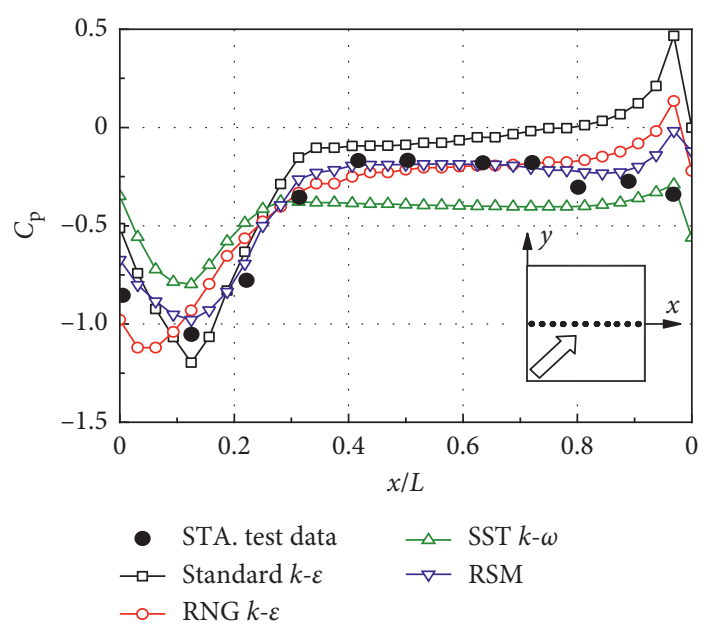

(b)

Figure 3: Experimental and numerical mean pressure coefficients along the central line of the flat roof. (a) $h_{\mathrm{p}} / H=0$, no parapet. (b) $h_{\mathrm{p}} / H=1 / 15$.

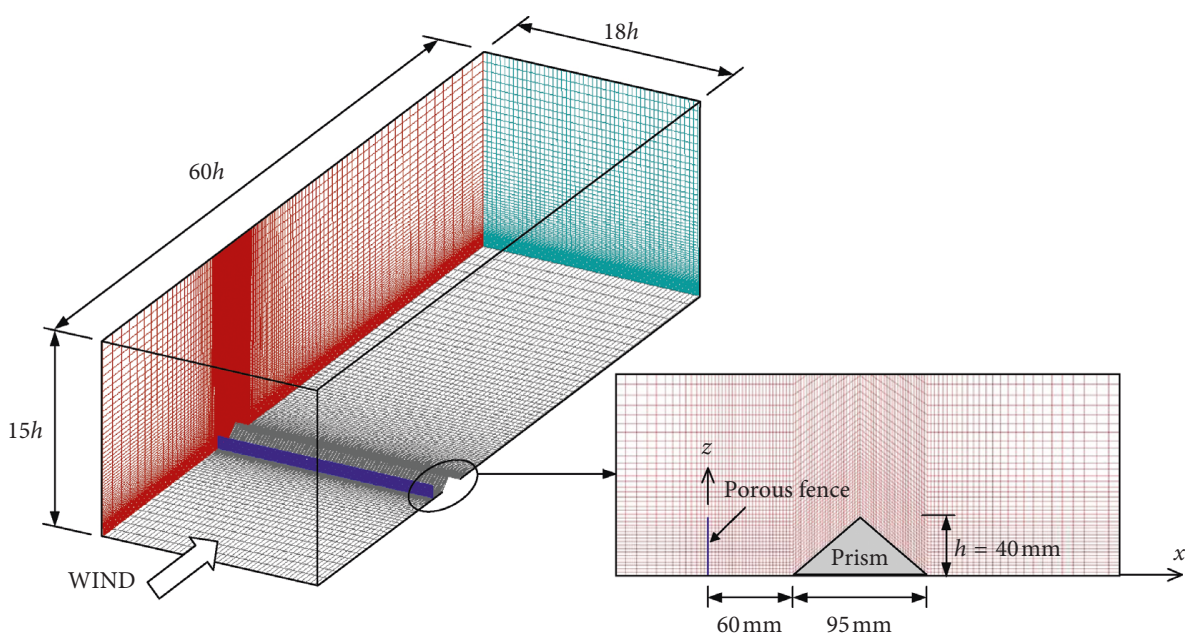

FIGURE 4: Schematic sketch of the computational domain and coordinate system of the fence and prism.

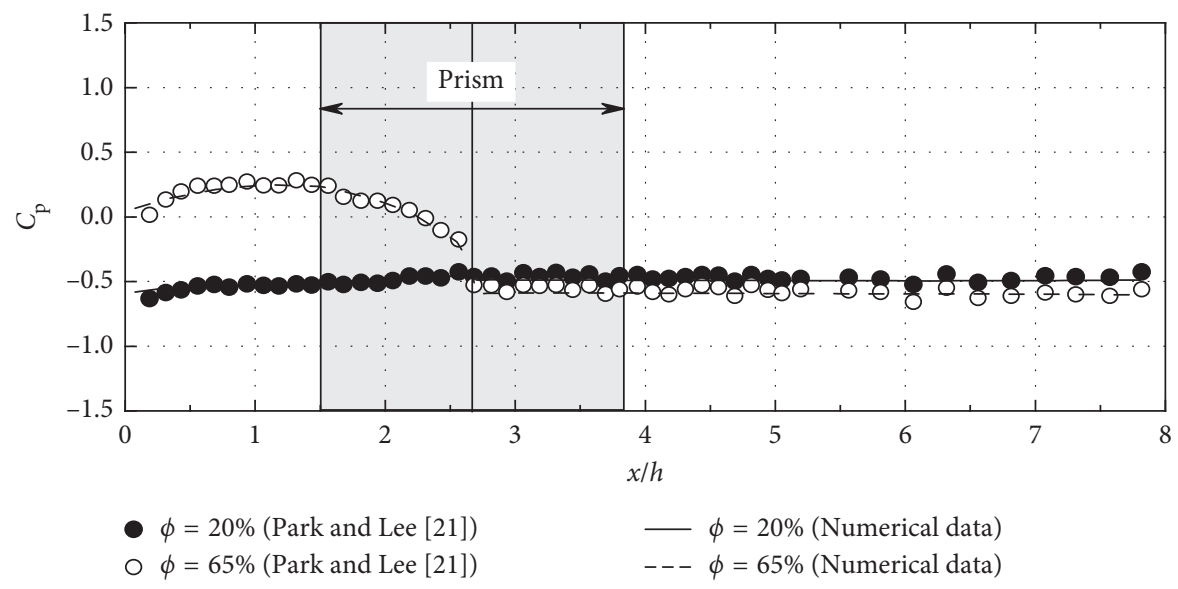

Figure 5: Comparison of the simulated and measured pressure distributions on the prism model and ground surface along the midspan of the fence. 
variables, objective functions, a flow solver, and an optimization algorithm. In the current study, the parapet porosity was chosen as the design variable, which is one of the most effective parameters for attenuating high corner suctions on building roof [9]. Thus, the aerodynamic porosity optimization problem can be described as follows:

$$
\begin{cases}\operatorname{Min} & F(\phi) \\ \text { s.t. } & l_{\phi} \leq \phi \leq u_{\phi},\end{cases}
$$

where $F(\phi)$ is the objective function, $\phi$ is the design variable, and $l_{\phi}$ and $u_{\phi}$ are, respectively, the lower and upper limits of the design variable.

Different goals of the porosity optimization allow the designer to explore more alternatives for the design of roofedge parapets. It is well known that high suctions are the result of conical vortices formed along the roof edge for oblique wind directions (Figure 6(a)), which are the main reason for most of wind-induced damages or wind-borne debris. It has been experimentally demonstrated that the highest mean suction occurs, in general, in the zone under the influence of conical vortices, in particular, beneath the average vortex core [36]. In addition, Banks et al. [37] have pointed out that the mean pressure profile is a reasonably accurate reflection of the typical shape of the instantaneous pressure profiles. Thus, the objective of the optimization in this study is defined to minimize the highest mean suction in the zone affected by conical vortices, and $F(\phi)$ is given by

$$
\operatorname{Min} F(\phi)=\max \left\{\left|C_{\mathrm{pi}, \mathrm{CACV}}(\phi)\right|\right\}
$$

where $C_{\mathrm{pi}, \mathrm{CACV}}(\phi)$ is the mean pressure coefficient of the $i$ th node in the case of porosity $\phi$, and the subscript CACV represents the coverage area of conical vortices. CACV can be judged by mean pressure profiles along lines normal to the windward edge, which exhibit bell-shaped suction curves as shown in Figure 6(b). It is generally accepted that the inflection point in mean suction profiles, where the suction gradient reaches its maximal, is considered as the reattachment position (coverage area) of conical vortices. The above objective function will be evaluated through the CFD approach as discussed in Section 2.

3.2. Optimization Algorithm. The aerodynamic porosity optimization used in the current study can be treated as a single-objective optimization problem, and there exists a unique optimal solution. The strategy for solving the porosity optimization problem entails the utilization of the gradient algorithm. One of the key characteristics of this algorithm is that it computes faster than the nongradient based algorithms. The basic idea of the gradient based methods is that the objective function reaches its minimum or maximum in the gradient direction. The iterative algorithm of the gradient algorithm by means of design variable porosity $(\phi)$ is given as follows:

$$
\phi^{(i+1)}=\phi^{(i)}+\alpha_{i} \cdot d^{(i)}
$$

where $i$ is the iteration step, $\alpha_{i}$ is the search step size derived by the golden section method and $d^{(i)}$ is the negative gradient value and calculated by $d^{(i)}=-\nabla^{(i)} F(\phi)=-\partial F(\phi) / \partial \phi$. More details on the gradient algorithm can be found by Tsai et al. [38]. The convergence criterion of iteration is defined as

$$
\left|F^{(i+1)}(\phi)-F^{(i)}(\phi)\right| \leq \tau,
$$

where $\tau$ is the convergence tolerance, and the optimization procedure will terminate as $\tau \leq 1 \times 10^{-4}$.

Generally, the basic process for an aerodynamic porosity optimization consists of the following steps: (a) assume the initial design variable $\phi^{(i)}$ and objective function $F^{(i)}(\phi)$ based on CFD, where $i=0$; (b) update the design variable $\phi^{(i+1)}$ by the gradient algorithm, and compute the new objective function $F^{(i+1)}(\phi)$; (c) check the convergence criterion, if not satisfy, and (d) repeat the second and third steps until the convergence tolerance is satisfied. A general approach for the aerodynamic porosity optimization utilizing CFD is shown in Figure 7, which was implemented by a FORTRAN program for searching the optimal parapet porosity.

\section{Results and Discussions}

4.1. Effect of Parapet Height. It is clear that parapet height, $h_{\mathrm{p}}$, can significantly influence the roof corner suctions for oblique wind directions. Previous studies have shown that the solid parapet tends to raise the corner vortices above the roof surface, for instance Stathopoulos et al. [5]. Data indicates that the addition of low parapets $(<0.5 \mathrm{~m}$ in height) have been found to increase peak suction on the roof considerably, compared to the roof without a parapet. However, higher parapets $\left(h_{\mathrm{p}} \geq 1.0 \mathrm{~m}\right)$ can lead to a significant reduction in corner suctions. In the present study, CFD simulations of wind pressures on a flat-roof structure in STA's experiment were performed, for solid parapets with relative height $h_{\mathrm{p}} / H$ ranging from 0 to 0.2 , to verify the above previous findings.

Figure 8 shows the variation of the minimum mean pressure coefficients (i.e., highest mean suction), $C_{\text {pmin }}$, on the roof with the relative parapet height for a $45^{\circ}$ oblique wind direction. Experimental results of Pindado and Meseguer [9] are also included in Figure 8 for comparison, which are obtained from the same roof model used in present simulations. Wind tunnel tests have been carried out in type I atmospheric boundary layer, and the turbulence intensity of the free-stream flow at the roof height is $I_{\mathrm{u}}=2.5 \%$. It can be seen from Figure 8 that the present computation, in general, agrees well with the experimental results of Pindado and Meseguer [9]. As it was expected, the minimum mean pressure coefficients are significantly affected by the parapet height. It can be observed that the highest mean suction behind solid vertical parapets increases $\left(C_{\text {pmin }}\right.$ varies from -3.2 to -4.1$)$ with relative height ranging from 0 to 0.03 . However, in the $h_{\mathrm{p}} / H$ range from 0.03 to 0.11 , the worst suction load on the roof decreases drastically $\left(C_{\mathrm{p}}\right.$ from -4.1 to about -0.9 ) as the parapet height increases. Additionally, the highest mean suctions have been found to be nearly invariant when relative height $h_{\mathrm{p}} / H>0.11$. It should also be noted that, in contrast with roof model 


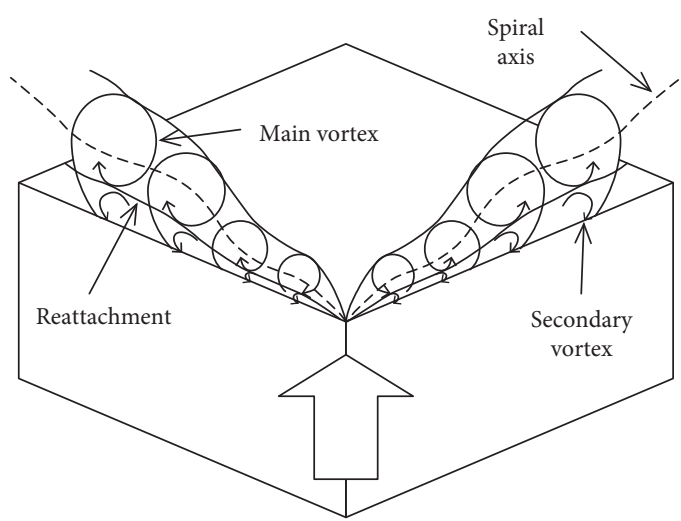

(a)

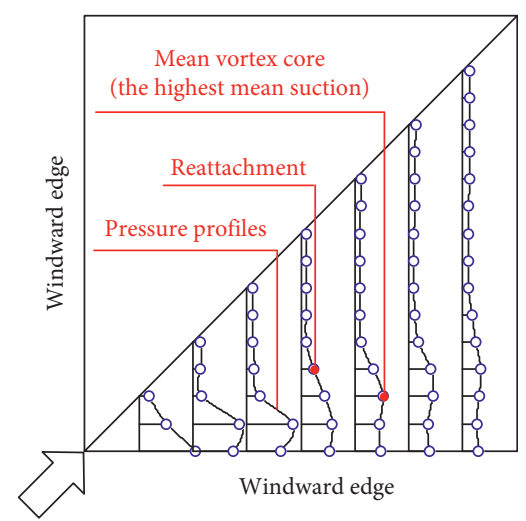

(b)

Figure 6: Conical vortices on a flat roof and corresponding mean suction profiles in oblique flow. (a) Conical vortices. (b) Mean suction profiles.

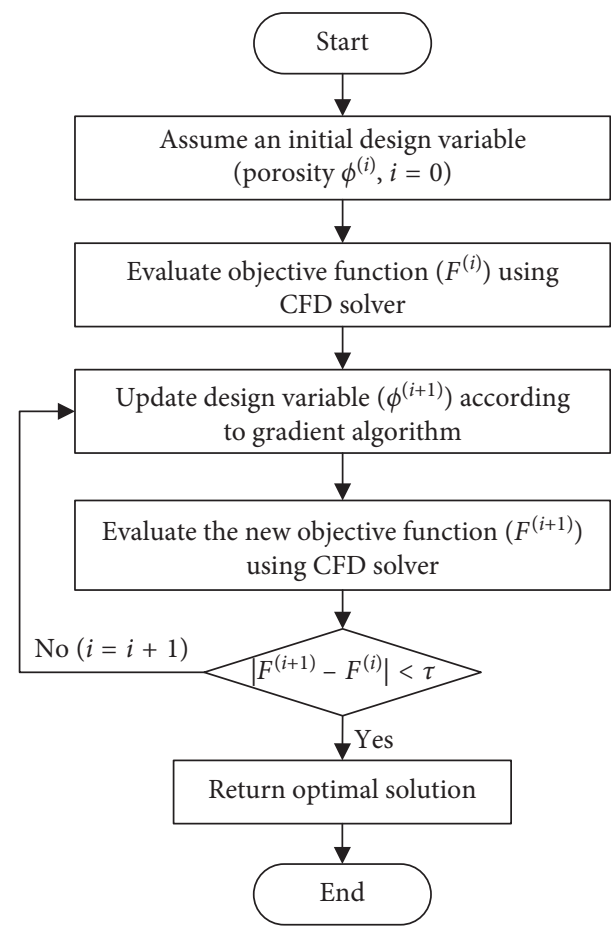

FIGURE 7: Flow chart of the CFD-based aerodynamic porosity optimization.

without parapets $\left(C_{\text {pmin }}=-3.2\right)$, solid parapets only produced an effective reduction of the wind loads $\left(\left|C_{\text {pmin }}\right|<3.2\right)$ on the roof when $h_{\mathrm{p}} / H \geq 0.07$.

To better understand the link between surface pressures and vortex behavior, Figure 9 displays mean pressure distributions on the flat roof exposed to conical vortices, together with mean suction profiles along lines normal to the leading edge. In this figure, numerical results of six solid parapets with relative heights ranging between 0 and 0.13 are presented. As is well known, the formation of conical vortices over a flat roof in oblique flow produces a symmetrical bell-shaped suction curve on the roof surface, with the maximum directly beneath the vortex core $[36,37]$. As a

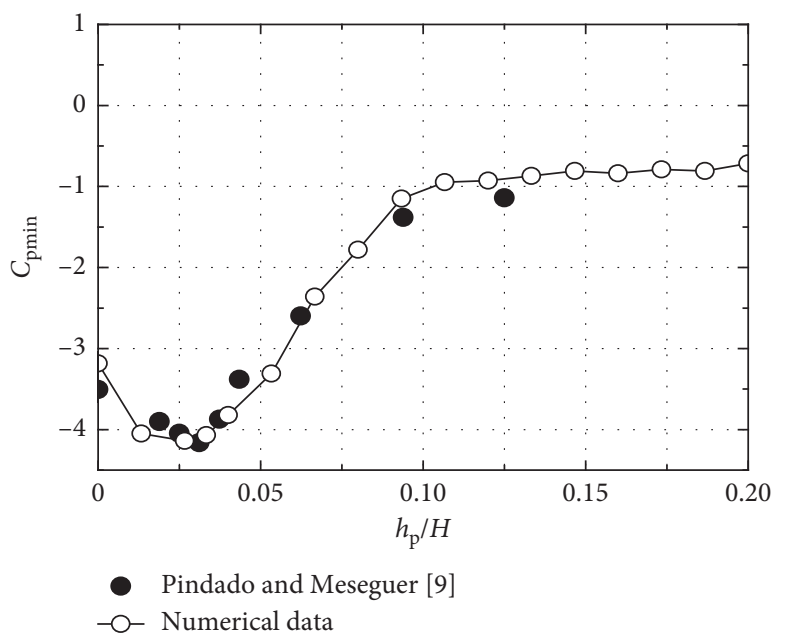

Figure 8: Variation of the highest mean suction on the roof with the relative parapet height $h_{\mathrm{p}} / H$.

result, the mean vortex core angle can be approximately ascertained as the angle formed between the leading edge and the rays of maximum mean suctions.

For parapets with $h_{\mathrm{p}} / H=0 \sim 0.07$, as shown in Figures 9(a)-9(e), the highest mean suction generally appears at a point closer to the roof corner than the mean vortex core, and it decreases with increasing distance from the corner. Mean suctions profiles are approximately bellshaped, and the generation and development of conical vortices are closely related with the parapet height. It can be observed that the size of the conical vortices gradually increases with increasing $h_{\mathrm{p}} / H$, whilst the vortex core angle increases from $12^{\circ}$ to $19^{\circ}$. Additionally, smaller parapet height $\left(h_{\mathrm{p}} / H \leq 0.03\right)$ could be less favorable to reduce the highest mean suction induced by conical vortices. The parapet with $h_{\mathrm{p}} / H=0.03$ (Figure $9(\mathrm{c})$ ) tends to create a more pronounced high-suction region at the leading edge of the roof. Larger reductions in $\left|C_{\text {pmin }}\right|$ can only be obtained as parapet height increases. This may be explained by the generation of eddy-turbulence wake downwind the parapets, 

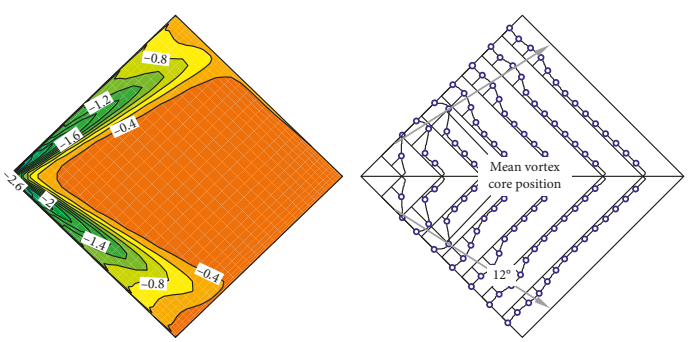

(a)
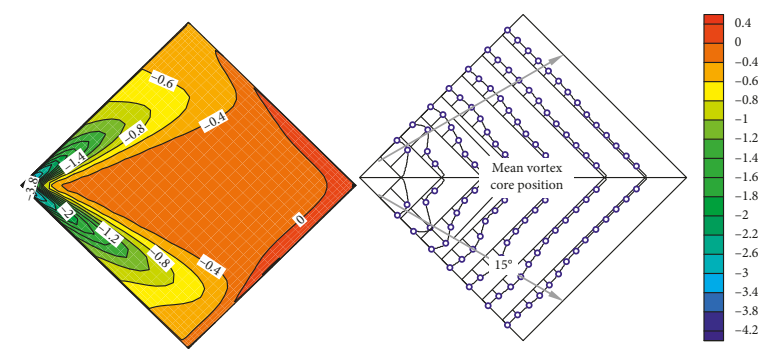

(c)
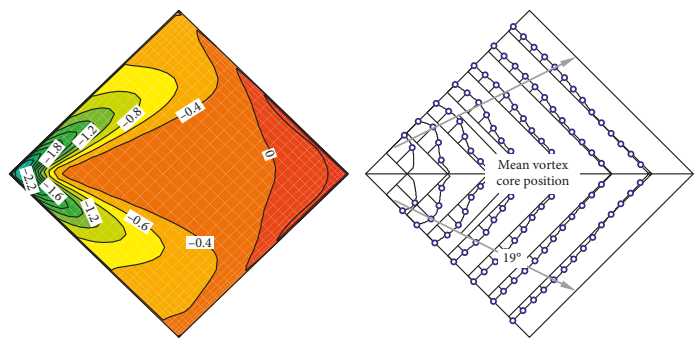

(e)
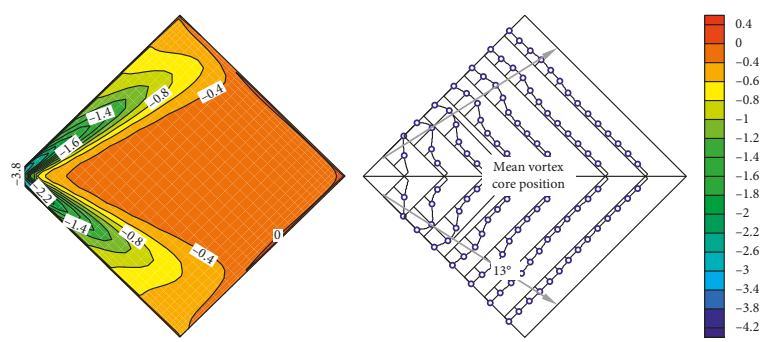

(b)
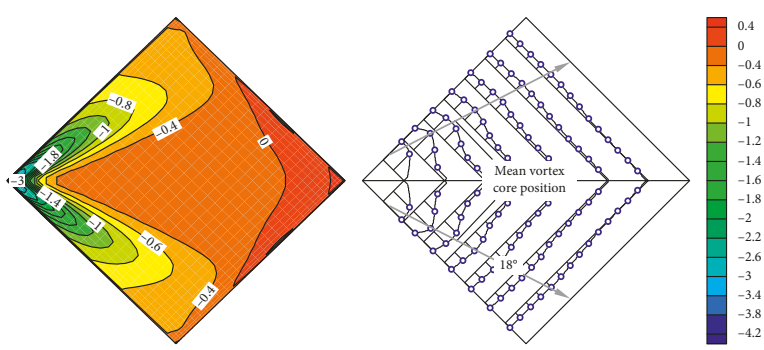

(d)
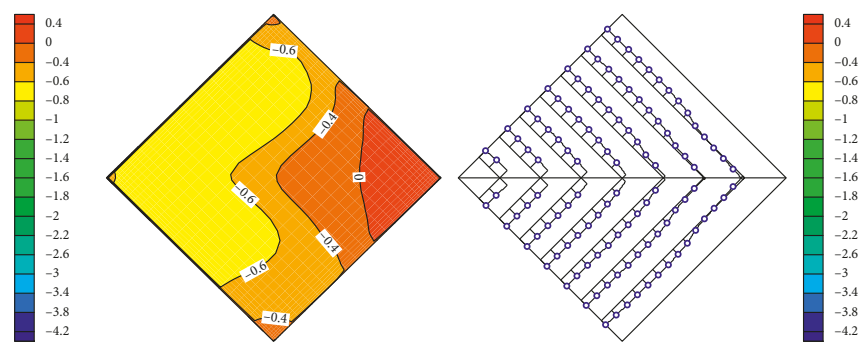

(f)

FIGURE 9: Contours of mean pressure coefficients and mean suction profiles on flat roofs with different relative parapet heights. (a) $h_{\mathrm{p}} / H=0$, no parapet. (b) $h_{\mathrm{p}} / H=0.01$. (c) $h_{\mathrm{p}} / H=0.03$. (d) $h_{\mathrm{p}} / H=0.05$. (e) $h_{\mathrm{p}} / H=0.07$. (f) $h_{\mathrm{p}} / H=0.13$.

which weakens the intensity of the vortex. In the case of $h_{\mathrm{p}} /$ $H=0.13$, as shown in Figure 9(f), it is interesting to note that surface pressures are uniformly distributed near the roof leading edge regardless of parapet height, and $\left|C_{\text {pmin }}\right|$ can be drastically reduced. This is because higher parapets tend to lift the conical vortices away from the roof surface, and consequently intense shear layers no longer interact with the roof surface.

4.2. Optimal Design of Porous Parapets. Currently, the porous parapets have been consistently found to be the most effective parapet configuration for mitigating the corner suctions on a flat roof [10]. Therefore, six case studies of porous parapets $\left(h_{\mathrm{p}} / H=0.01,0.03,0.05,0.07,0.09\right.$, and 0.13$)$ are considered, as the application of porosity optimization framework proposed in this work. The gradient algorithm was employed to find out the optimal porosity at a given parapet height, which provides the best performance for alleviating the high suctions on the roof surface. However, the main drawback of gradient algorithm is that it may converge to local minima. Thus, two initial porosities $\phi^{(0)}=$ $0 \%$ and $100 \%$ were used simultaneously to search the global optimal solution, which correspond to the lower and upper limits of the design variable, respectively. The optimization procedure will terminate when the change in objective function between iterations reduces below $1 \times 10^{-4}$.

Figure 10 shows the variations with relative parapet height, $h_{\mathrm{p}} / H$, of the highest mean suctions resulting from solid parapets and parapets with optimal porosity. It can be seen that, in the $h_{\mathrm{p}} / H$ range between 0.01 and $0.05,\left|C_{\text {pmin }}\right|$ for parapets with optimal porosity are at least $26 \%$ smaller in magnitude than those for the solid parapet and also smaller than the no parapet case. For parapets with $h_{\mathrm{p}} / H=0.01,0.03$, and 0.05 , the optimal porosities are $52.3 \%, 47.7 \%$, and $38.2 \%$, respectively. Note that, when $h_{\mathrm{p}} / H \geq 0.07$, porous parapets are almost useless in reducing high suctions on the roof surface, as compared to the solid parapet. The optimal porosity for the optimization case of $h_{\mathrm{p}} / H=0.07$ is about $15.5 \%$, but only $2.5 \%$ reduction in the magnitude of $\left|C_{\mathrm{pmin}}\right|$ is obtained compared to the solid parapet case. It should also be noted that solid parapets are found to be the most effective for mitigating corner suctions when $h_{\mathrm{p}} / H \geq 0.09$, i.e., optimal porosity $\phi=0 \%$, due to the weaken vortices are displaced away from the roof surface.

Figure 11 shows contours of mean pressure coefficients and mean suction profiles on the flat roof obtained from the porosity optimizations, with relative parapet height ranging between 0.01 and 0.07. As shown in Figures 9(b)-9(e) and Figure 11, the patterns of mean pressure distributions, along 


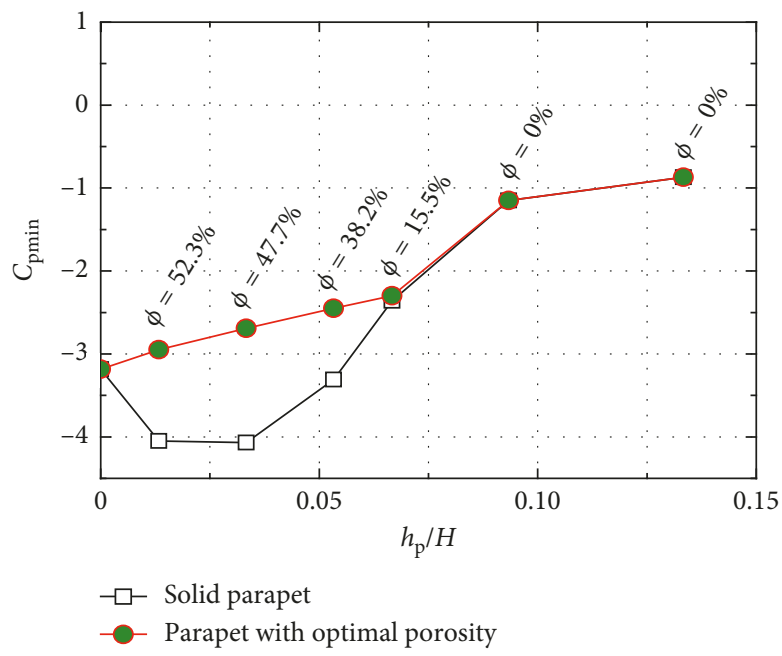

FIGURE 10: Comparison of the highest mean suctions between roof models with solid parapets and the parapets having optimal porosity.
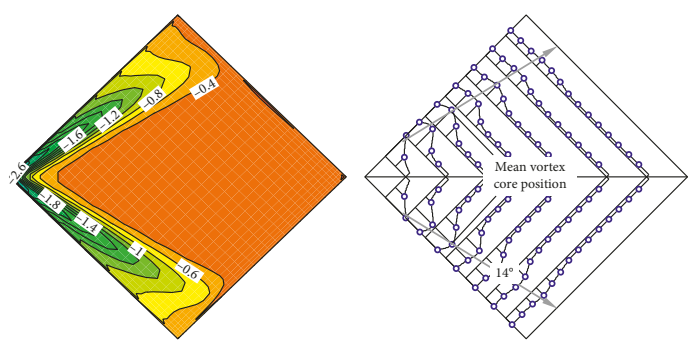

(a)

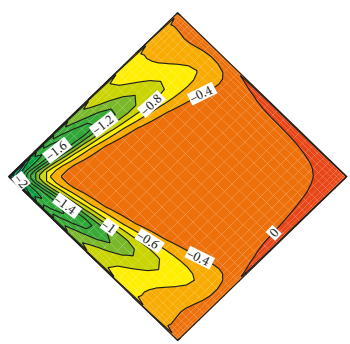

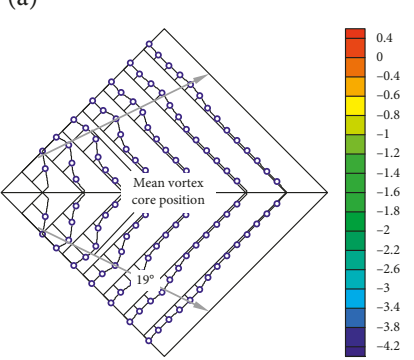

(c)

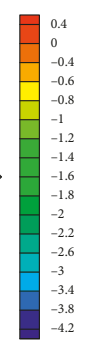

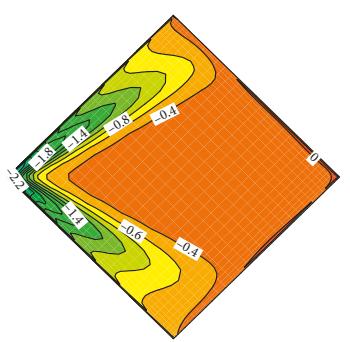

(b)

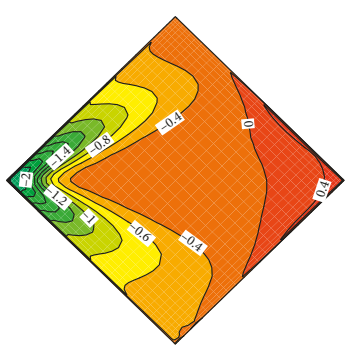

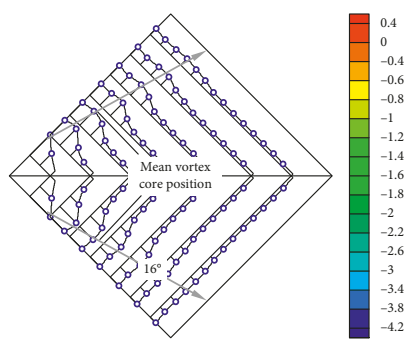

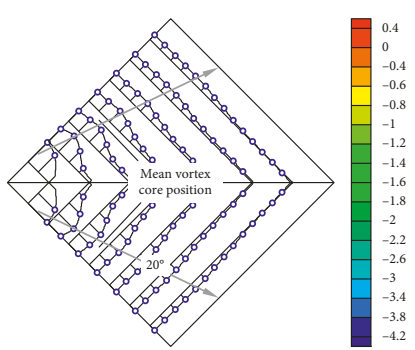

(d)

FIgURE 11: Contours of mean pressure coefficients and mean suction profiles on flat roofs with optimal parapet porosities, for different relative parapet height cases. (a) $h_{\mathrm{p}} / H=0.01 \quad(\phi=52.3 \%)$. (b) $h_{\mathrm{p}} / H=0.03 \quad(\phi=47.7 \%)$. (c) $h_{\mathrm{p}} / H=0.05 \quad(\phi=38.2 \%)$. (d) $h_{\mathrm{p}} / H=0.07$ $(\phi=15.5 \%)$.

with the formation and dimension of conical vortices, between solid parapets and optimized porous parapets are similar. However, porous parapets with optimal porosity are more effective than solid parapets to reduce the high suctions appearing at the leading corner of the roof, especially when the relative parapet height is lower than 0.05 . The difference in corner suction reduction between solid and optimized porous parapets becomes smaller as the relative parapet height increases up to $h_{\mathrm{p}} / H=0.07$.

\section{Conclusions}

The current study introduces an aerodynamic porosity optimization procedure that combines gradient algorithm and 3D CFD simulations based on the RANS equations. The applicability of the proposed optimization procedure was investigated using the example of a flat roof with porous parapets located at the roof edges. The goal was to determine an optimal porosity to minimize the high-suction loads on the roof surface caused by conical vortices. The contributions of this paper can be summarized as follows:

(i) CFD simulations utilizing four turbulence closure models (standard $k-\varepsilon$, RNG $k-\varepsilon$, SST $k-\omega$, and RSM) were conducted for the prediction of the windinduced pressure distributions on a $3 \mathrm{D}$ flat roof with solid and porous parapets. The simulation results from the RSM model were in relatively good agreement with the wind tunnel data by 
Stathopoulos et al. [5]. Additionally, the prediction results of the porous media flow using the pressure loss in the momentum equation were well agreed with the experimental results by Park and Lee [21]. As a result, the numerical method was proved to be useful and appropriate to predict the effect of solid or porous parapets on the pressure distribution on the roof surface.

(ii) Six optimization case studies of roof-edge parapets with $h_{\mathrm{p}} / H$ ranging between 0.01 and 0.13 were presented to demonstrate the potential of the proposed optimization approach. It was found that for low-height parapets with $h_{\mathrm{p}} / H=0.01,0.03$, and 0.05 , the highest mean suction is reduced by $26 \%$ at least for the optimal parapets (optimal porosities are $52.3 \%, 47.7 \%$, and $38.2 \%$ respectively), as compared to the solid parapet, whereas for high-height parapets $\left(h_{\mathrm{p}} / H \geq 0.07\right)$, solid parapet seems to be most effective in eliminating the formation of conical vortices and reducing the highest mean suction on the roof surface. Generally speaking, the aerodynamic porosity optimization efficiency coupled with the extensive development in computational capacity is expected to encourage designers to seek for more optimal solutions while alleviating the high suctions appearing on the roof.

The main limitations of this work have been the restricted free-stream flow conditions and limited design height of the parapet. Further study needs to be conducted to evaluate the performance of the optimal parapet designs under different turbulent boundary conditions, and to explore a multiparameter design space to consider both the porosity and height of the parapet.

\section{Data Availability}

All data used to support the findings of this study are available from the corresponding author upon request.

\section{Conflicts of Interest}

The authors declare that there are no conflicts of interest regarding the publication of this paper.

\section{Acknowledgments}

This study was financially supported by the National Natural Science Foundation of China under grant nos. 51808194 and 51578211, the Fundamental Research Funds for the Central Universities under grant no. 2018B13814, the Natural Science Foundation of Jiangsu Province under grant no. BK20170880, and the China Postdoctoral Science Foundation under grant no. 2016M591754.

\section{References}

[1] H. Kawai and G. Nishimura, "Characteristics of fluctuating suction and conical vortices on a flat roof in oblique flow,"
Journal of Wind Engineering and Industrial Aerodynamics, vol. 60, pp. 211-225, 1996.

[2] P. Huang, X. Peng, and M. Gu, "Wind tunnel study on effects of various parapets on wind load of a flat-roofed low-rise building," Advances in Structural Engineering, vol. 20, no. 12, pp. 1907-1919, 2017.

[3] G. A. Kopp, D. Surry, and C. Mans, "Wind effects of parapets on low buildings: Part 1. Basic aerodynamics and local loads," Journal of Wind Engineering and Industrial Aerodynamics, vol. 93, no. 11, pp. 817-841, 2005.

[4] G. Li, S. Gan, and H. Li, "Wind pressure mitigation on gable roofs for low-rise buildings using spoilers," Journal of Structural Engineering, vol. 144, no. 8, article 04018104, 2018.

[5] T. Stathopoulos, P. Saathoff, and X. Du, "Wind loads on parapets," Journal of Wind Engineering and Industrial Aerodynamics, vol. 90, no. 4-5, pp. 503-514, 2002.

[6] W. Suaris and P. Irwin, "Effect of roof-edge parapets on mitigating extreme roof suctions," Journal of Wind Engineering and Industrial Aerodynamics, vol. 98, no. 10-11, pp. 483-491, 2010.

[7] D. Surry and J. X. Lin, "The effect of surroundings and roof corner geometric modifications on roof pressures on low-rise buildings," Journal of Wind Engineering and Industrial Aerodynamics, vol. 58, no. 1-2, pp. 113-138, 1995.

[8] D. Banks, The suction induced by conical vortices on low-rise buildings with flat roofs, Ph.D. thesis, Colorado State University, Fort Collins, CO, USA, 2000.

[9] S. Pindado and J. Meseguer, "Wind tunnel study on the influence of different parapets on the roof pressure distribution of low-rise buildings," Journal of Wind Engineering and Industrial Aerodynamics, vol. 91, no. 9, pp. 1133-1139, 2003.

[10] G. A. Kopp, C. Mans, and D. Surry, "Wind effects of parapets on low buildings: Part 4. Mitigation of corner loads with alternative geometries," Journal of Wind Engineering and Industrial Aerodynamics, vol. 93, no. 11, pp. 873-888, 2005.

[11] American Society of Civil Engineers (ASCE), "Minimum design loads for buildings and other structures," in ASCE 7-16, American Society of Civil Engineers (ASCE), Reston, VA, USA, 2016.

[12] J. X. Lin, P. R. Montpellier, C. W. Tillman, and W. Riker, "Aerodynamic devices for mitigation of wind damage risk," in Proceedings of the 4th International Conference on Advances in Wind and Structures, Jeju, Korea, May 2008.

[13] C. Blessing, A. G. Chowdhury, J. Lin, and P. Huang, "Fullscale validation of vortex suppression techniques for mitigation of roof uplift," Engineering Structures, vol. 31, no. 12, pp. 2936-2946, 2009.

[14] A. Poitevin, B. Natalini, and L. A. Godoy, "Pressures on open canopy structures with parapets under wind loading," Engineering Structures, vol. 56, pp. 850-867, 2013.

[15] J. Liu, Y. Q. Yang, Y. L. Sun, and B. He, "Simulation study on the wind pressure of village flat roof with parapet based on different wind angles," Applied Mechanics and Materials, vol. 638-640, pp. 228-232, 2014.

[16] Q. S. Li and S. Liu, "Large eddy simulation of the characteristics of conical vortex on a flat roof," Journal of Hunan University (Natural Sciences), vol. 42, no. 11, pp. 72-79, 2015, in Chinese.

[17] A.-M. Aly and J. Bresowar, "Aerodynamic mitigation of windinduced uplift forces on low-rise buildings: a comparative study," Journal of Building Engineering, vol. 5, pp. 267-276, 2016.

[18] J.-E. Kim, V. N. Rao, R. P. Koomullil, D. H. Ross, B. K. Soni, and A. M. Shih, "Development of an efficient aerodynamic 
shape optimization framework," Mathematics and Computers in Simulation, vol. 79, no. 8, pp. 2373-2384, 2009.

[19] M. A. Mooneghi and R. Kargarmoakhar, "Aerodynamic mitigation and shape optimization of buildings: review," Journal of Building Engineering, vol. 6, pp. 225-235, 2016.

[20] B. San, Y. Wang, and Y. Qiu, "Numerical simulation and optimization study of the wind flow through a porous fence," Environmental Fluid Mechanics, vol. 18, no. 5, pp. 1057-1075, 2018.

[21] C. W. Park and S. J. Lee, "Experimental study on surface pressure and flow structure around a triangular prism located behind a porous fence," Journal of Wind Engineering and Industrial Aerodynamics, vol. 91, no. 1-2, pp. 165-184, 2003.

[22] L. Guo and R. G. Maghirang, "Numerical simulation of airflow and particle collection by vegetative barriers," Engineering Applications of Computational Fluid Mechanics, vol. 6, no. 1, pp. 110-122, 2012.

[23] M. Rosenfeld, G. Marom, and A. Bitan, "Numerical simulation of the airflow across trees in a windbreak," BoundaryLayer Meteorology, vol. 135, no. 1, pp. 89-107, 2010.

[24] C.-F. Song, L. Peng, J.-J. Cao, L. Mu, H.-L. Bai, and X.-F. Liu, "Numerical simulation of airflow structure and dust emissions behind porous fences used to shelter open storage piles," Aerosol and Air Quality Research, vol. 14, no. 6, pp. 15841592, 2014.

[25] P. Richards and R. P. Hoxey, "Appropriate boundary conditions for computational wind engineering models using the $k$ - $\varepsilon$ turbulence model," Journal of Wind Engineering and Industrial Aerodynamics, vol. 46-47, pp. 145-153, 1993.

[26] J. L. Santiago and F. Martin, "Modelling the air flow in symmetric and asymmetric street canyons," International Journal of Environment and Pollution, vol. 25, no. 1-4, pp. 145-154, 2005.

[27] M. De Gennaro, A. Hueppe, H. Kuehnelt, and M. Kaltenbacher, "Numerical prediction of laminar instability noise for naca 0012 aerofoil," AIP Conference Proceedings, vol. 1389, no. 1, pp. 78-81, 2011.

[28] J. L. Santiago, F. Martín, A. Cuerva, N. Bezdenejnykh, and A. Sanz-Andrés, "Experimental and numerical study of wind flow behind windbreaks," Atmospheric Environment, vol. 41, no. 30, pp. 6406-6420, 2007.

[29] S. V. Patankar and D. B. Spalding, Numerical Prediction of Flow, Heat Transfer, Turbulence and Combustion, Pergamon Press Inc., New York, NY, USA, 1983.

[30] M. G. Gomes, A. Moret Rodrigues, and P. Mendes, "Experimental and numerical study of wind pressures on irregular-plan shapes," Journal of Wind Engineering and Industrial Aerodynamics, vol. 93, no. 10, pp. 741-756, 2005.

[31] K. A. Papakonstantinou, C. T. Kiranoudis, and N. C. Markatos, "Numerical simulation of air flow field in single-sided ventilated buildings," Energy and Buildings, vol. 33, no. 1, pp. 41-48, 2000.

[32] A. K. Dagnew and G. T. Bitsuamlak, "Computational evaluation of wind loads on buildings: a review," Wind and Structures, vol. 16, no. 6, pp. 629-660, 2013.

[33] S.-J. Lee and H.-C. Lim, "A numerical study on flow around a triangular prism located behind a porous fence," Fluid Dynamics Research, vol. 28, no. 3, pp. 209-221, 2001.

[34] J. D. Wilson, "Numerical studies of flow through a windbreak," Journal of Wind Engineering and Industrial Aerodynamics, vol. 21, no. 2, pp. 119-154, 1985.

[35] A. J. Reynolds, "Flow deflection by gauze screens," Journal of Mechanical Engineering Science, vol. 11, no. 3, pp. 290-294, 1969.
[36] X. Dong and J. Ye, "The point and area-averaged wind pressure influenced by conical vortices on saddle roofs," Journal of Wind Engineering and Industrial Aerodynamics, vol. 101, pp. 67-84, 2012.

[37] D. Banks, R. N. Meroney, P. P. Sarkar, Z. Zhao, and F. Wu, "Flow visualization of conical vortices on flat roofs with simultaneous surface pressure measurement," Journal of Wind Engineering and Industrial Aerodynamics, vol. 84, no. 1, pp. 65-85, 2000.

[38] C. H. Tsai, J. Kolibal, and M. Li, "The golden section search algorithm for finding a good shape parameter for meshless collocation methods," Engineering Analysis with Boundary Elements, vol. 34, no. 8, pp. 738-746, 2010. 


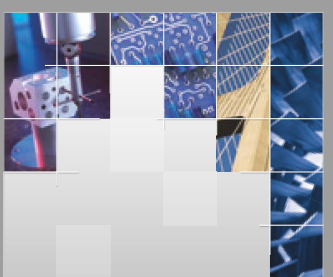

\section{Enfincering}
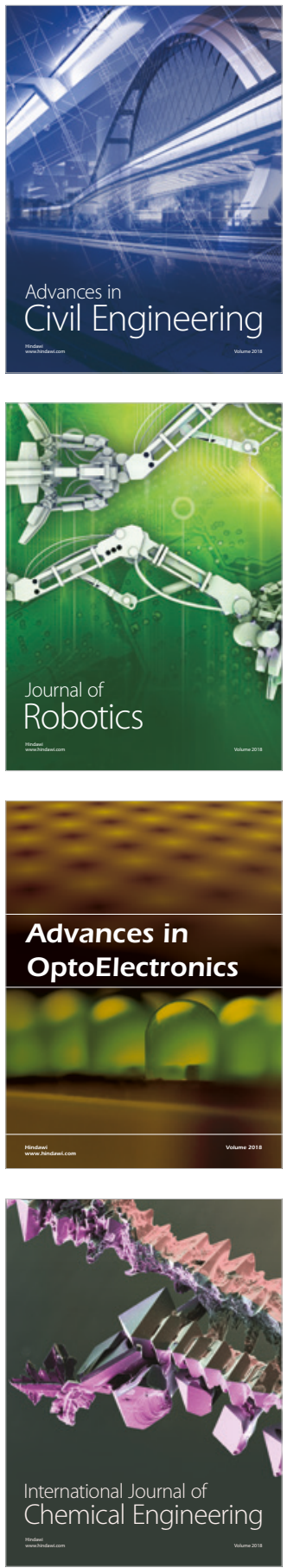

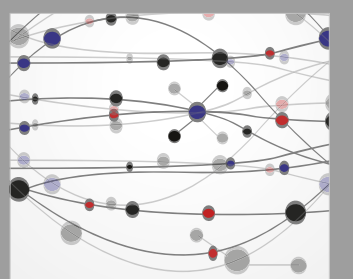

\section{Rotating \\ Machinery}

The Scientific World Journal

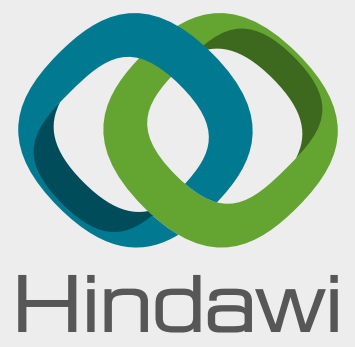

Submit your manuscripts at

www.hindawi.com
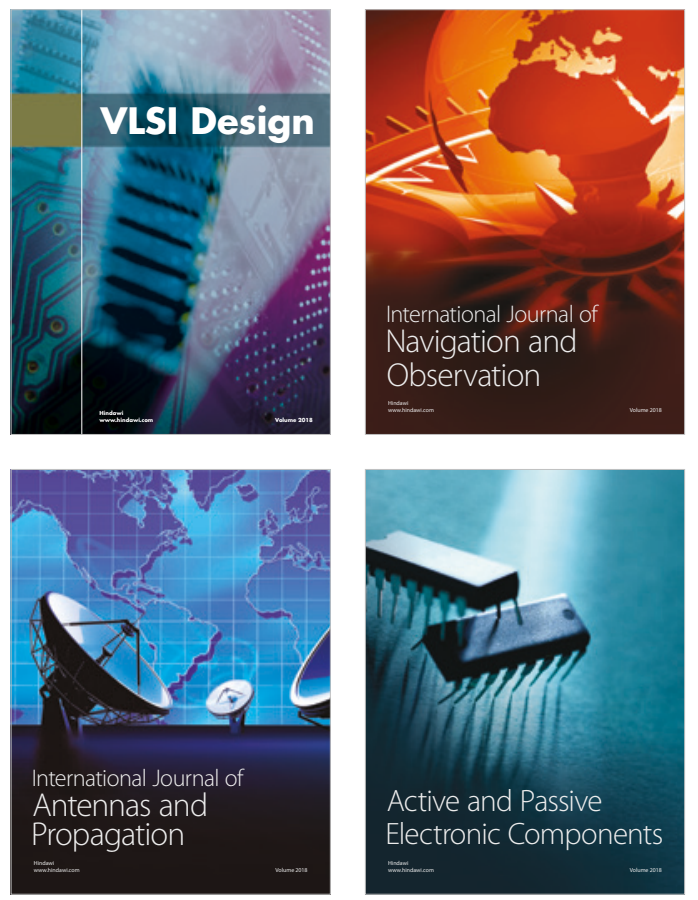
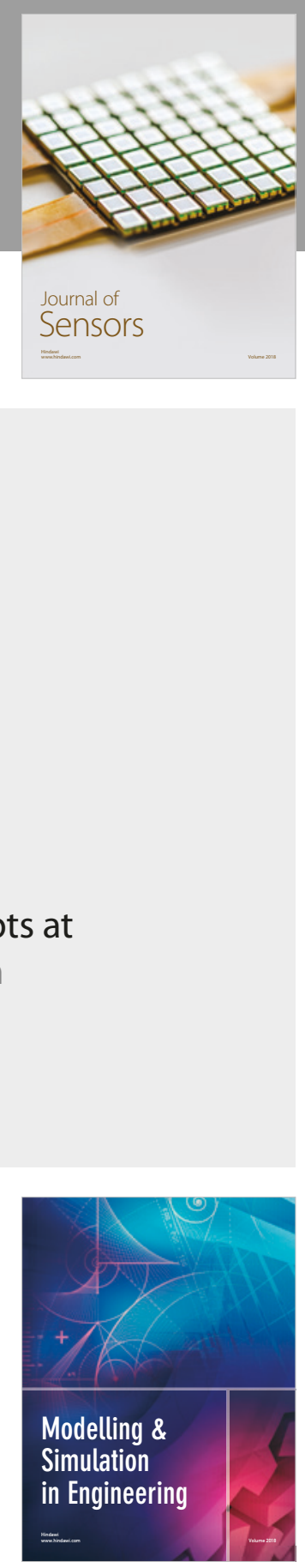

\section{Advances \\ Multimedia}
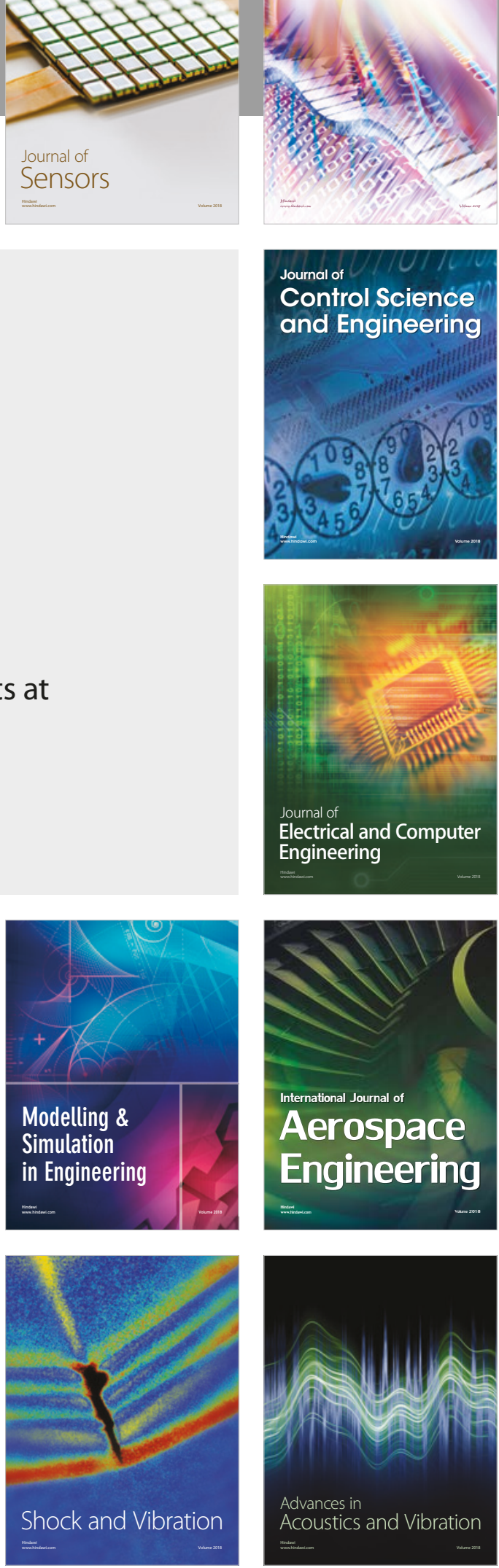